\title{
Altered glutamate cysteine ligase expression and activity in renal cell carcinoma
}

\author{
MONONG LI ${ }^{1,2^{*}}$, ZONGLIANG ZHANG $^{2 *}$, JIANGSHUI YUAN $^{2}$, YANLUN ZHANG $^{2}$ and XUNBO JIN ${ }^{1,3}$ \\ ${ }^{1}$ School of Medicine, Shandong University, Jinan, Shandong 250012; ${ }^{2}$ Qingdao Municipal Hospital, Qingdao, \\ Shandong 266071; ${ }^{3}$ Provincial Hospital Affiliated to Shandong University, \\ Shandong University, Jinan, Shandong 250021, P.R. China
}

Received June 3, 2014; Accepted July 21, 2014

DOI: $10.3892 /$ br.2014.359

\begin{abstract}
Oxidative stress has been linked to the progression of mutations and cancer. Increased glutathione (GSH) contents have been observed in a number of different human cancer tissues. GSH is synthesized de novo in a two-step process catalyzed by glutamate cysteine ligase (GCL). The present study aimed to investigate whether GCL was associated with renal cell carcinoma (RCC). The protein expression levels of the GCL subunits (catalytic subunit, GCLc; and modulatory subunit, GCLm) and GCL activity were examined in renal cancer tissue. A total of 46 patients fulfilling the RCC criteria of the World Health Organization, revised in 2004, were enrolled. The tumor and adjacent tissues were sampled from all the subjects by surgery. The study demonstrated that GCLc and GCLm protein expression and the GCL activity were significantly increased in the tumor tissue from RCC patients. These results indicate that increased expression and enzymatic activity of GCL is closely associated with RCC and thus, this suggests an important role for GSH in the pathogenesis of RCC.
\end{abstract}

\section{Introduction}

Renal cell carcinoma (RCC) is the most common malignant tumor of the kidney and incidence has been increasing worldwide (1). The pathogenesis and diagnosis of the prognosis for patients with RCC has remained poor, regardless of the

Correspondence to: Professor Xunbo Jin, School of Medicine, Shandong University, 44 Wenhua Xi Rd, Jinan, Shandong 250012, P.R. China

E-mail: qdsl_wk@163.com

Professor Yanlun Zhang, Qingdao Municipal Hospital, 1 Jiaozhou Rd, Qingdao, Shandong 266071, P.R. China

E-mail: abraham315@sohu.com

*Contributed equally

Key words: glutamate cysteine ligase, renal cell carcinoma, oxidative stress extensive clinical trials that have been performed (2-4). There are numerous components that comprise the tumor environment, each of which allows for an advantageous environment for survival (5). Oxidative stress has been linked to the progression of mutations and cancer. In the case of a cancer cell, a significant imbalance between reactive oxygen species/reactive nitrogen species production and antioxidant defense can explain all the findings associated with tumor growth and a state of high oxidative stress, such as loss of redox homeostasis (6). Hypoxia is a general characteristic of solid tumors (7). Increased glutathione (GSH) contents have been observed in a number of different human cancer tissues, including breast, brain, colon, pancreas, lungs, head and neck cancer and leukemia (8-14). High intracellular GSH levels are important contributors to pathologies, such as cellular transformation, resistance to radiation and antineoplastic treatments in cancer cells (15).

GSH is synthesized de novo in a two-step process catalyzed by glutamate cysteine ligase (GCL, EC 6.3.2.2), previously known as $\gamma$-glutamylcysteine synthetase and GSH synthetase (GS; EC 6.3.2.3). GCL catalyzes the first and rate-limiting step, in which glutamate is ligated with cysteine to form $\gamma$-glutamylcysteine $(\gamma-\mathrm{GC})$, which is rapidly linked to glycine to form GSH via the action of GS (16). GCL is a heterodimeric enzyme consisting of a catalytic subunit (GCLc) and a modulatory subunit (GCLm), which are encoded by two genes (17). GCLc performs all the enzymatic activity and its catalytic efficiency is increased by the covalent interaction with GCLm $(18,19)$. GSH can be depleted through the specific downregulation of the GCL levels by hammerhead ribozyme. Ribozymes have been shown to deplete GSH levels by inhibiting GCLc and GCLm, and enhancing anticancer drug sensitivity (20). The aim of the present study was to evaluate the change of GCL expression and activity in RCC patients.

\section{Materials and methods}

Patients and controls. A total of 46 patients with clear cell RCC fulfilling the RCC criteria of World Health Organization, revised in 2004 (21), were enrolled for the study. The tumor tissue and adjacent normal tissue were sampled from all the patients through surgery. Staging of 46 RCC patients, including 12 of stage I, 10 of stage II, 18 of stage III and six of stage IV, was assessed by the tumor-node metastasis (TNM) staging system 
for kidney cancer revised by American Joint Committee on Cancer (22). In total, 46 RCC patients were confirmed through pathology. All the patients signed an informed consent form prior to the initiation of the study. All the samples from the patients were analyzed and approved by the Ethics Committee of Qingdao Municipal Hospital (Qingdao, Shandong, China).

GCL activity assay. GCL activity was determined by the fluorescence assay described by Chen et al (23). Tumor tissue and adjacent tissues for comparison from RCC patients were homogenized in $20 \mathrm{mmol} / \mathrm{l}$ Tris- $\mathrm{HCl}, 1 \mathrm{mmol} / \mathrm{l}$ EDTA, $250 \mathrm{mmol} / \mathrm{l}$ sucrose, $20 \mathrm{mmol} / 1$ sodium borate and $2 \mathrm{mmol} / \mathrm{l}$ serine $[$ TES/SB buffer $(\mathrm{w} / \mathrm{v}=1 / 4)]$ and sonicated at $100 \mathrm{~W}$ for $60 \mathrm{sec}$. The mixtures were centrifuged at $10,000 \mathrm{x}$ g at $4^{\circ} \mathrm{C}$ for $10 \mathrm{~min}$ and the supernatants were collected. The samples were centrifuged again at $15,000 \mathrm{x}$ g at $4^{\circ} \mathrm{C}$ for $20 \mathrm{~min}$ and the supernatants were collected. The protein concentrations were determined using the bicinchoninic acid (BCA) Protein Assay kit (Beyotime Institute of Biotechnology, Shanghai, China), with bovine serum albumin as the standard.

For the GCL activity assay, $30 \mu 1$ supernatant aliquots were mixed with $30 \mu \mathrm{l}$ GCL-reaction cocktail [ $400 \mathrm{mmol} / \mathrm{l}$ Tris- $\mathrm{HCl}$, $40 \mathrm{mmol} / \mathrm{l}$ adenosine triphosphate (ATP), $40 \mathrm{mmol} / \mathrm{l} \mathrm{L}$-glutamic acid, $2 \mathrm{mmol} / 1 \mathrm{EDTA}, 20 \mathrm{mmol} / 1$ sodium borate, $2 \mathrm{mmol} / 1$ serine and $40 \mathrm{mmol} / 1 \mathrm{MgCl}_{2}$ ]. After incubation at $37^{\circ} \mathrm{C}$ for $5 \mathrm{~min}, 30$ $\mu 130 \mathrm{mmol} / 1$ cysteine solution (dissolved in TES/SB buffer) was added and the mixtures were incubated at $37^{\circ} \mathrm{C}$ for $13 \mathrm{~min}$. The enzymatic reaction in the mixtures was stopped by precipitation of proteins with $200 \mathrm{mmol} / \mathrm{l}$ 5-sulfosalicylic acid (SSA). After placing the samples on ice for $20 \mathrm{~min}$, the mixtures were centrifuged at $2,000 \mathrm{x} \mathrm{g}$ at $4^{\circ} \mathrm{C}$ for $10 \mathrm{~min}$. Following centrifugation, $20 \mu \mathrm{l}$ of each supernatant that contained the $\gamma$-GC product was added to a 96-well plate designed for fluorescence detection. For each assay, $20 \mu \mathrm{l} \gamma$-GC standards containing $5 \mu \mathrm{l} \mathrm{GCL}$

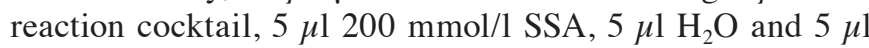
$\gamma$-GC standard solution $(0,20,40,60,80,100,120$ or $140 \mu \mathrm{M}$ $\gamma$-GC in TES/SB buffer) was added to each well of the same 96-well plate to generate the standard curve. Subsequently, $180 \mu 1$ 2,3-naphthalenedicarboxyaldehyde (NDA) was added into each well. After incubation in the dark at room temperature for $30 \mathrm{~min}$, the formation of NDA- $\gamma$-GC was measured (472 nm excitation/528 nm emission) using a fluorescent plate reader (GENios Plus; Tecan Group Ltd., Männedorf, Switzerland). The production of $\gamma$-GC in each sample was calculated with a standard curve. The values are expressed in millimoles per min per milligram protein.

Western blotting. The protein contents of the GCLc and GCLm subunits of GCL were determined by western blotting, as described by Chen et al (23). Briefly, the tumor and adjacent tissues for comparison from RCC patients were homogenized, respectively, in DNase buffer containing $20 \mathrm{mmol} / \mathrm{l}$ Tris- $\mathrm{HCl}$ (pH 6.8), $1 \mathrm{mmol} / 1 \mathrm{CaCl}_{2}, 5 \mathrm{mmol} / 1 \mathrm{MgCl}_{2}$ and $150 \mathrm{U} / \mathrm{ml}$ DNase I (Takara Bio, Inc., Dalian, China). The homogenates were placed on ice for $40 \mathrm{~min}$ and mixed with the same volume of urea buffer containing $6 \mathrm{M}$ urea, $2 \%$ sodium dodecyl sulfate (SDS) and $20 \mathrm{mmol} / 1 \mathrm{Tris}-\mathrm{HCl}(\mathrm{pH}$ 6.8). The mixtures were centrifuged at $600 \mathrm{xg}$ at $4^{\circ} \mathrm{C}$ for $15 \mathrm{~min}$ and the supernatants were collected. The protein concentrations in the supernatants were determined using the BCA Protein Assay kit as aforementioned. The supernatants containing equal amounts of protein (20 $\mu \mathrm{g}$ for GCLc and $50 \mu \mathrm{g}$ for GCLm as determined by the linear responses of respective antibody) were loaded onto $12 \%$ SDS-polyacrylamide gels and separated by electrophoresis using Mini-Vertical Gel Electrophoresis Units (Bio-Rad, Hercules, CA, USA). The proteins that were resolved on the gels were transferred to polyvinylidene difluoride (PVDF) membranes using a Trans-Blot Semi-Dry Transfer Cell (Trans-Blot; Bio-Rad) at $10 \mathrm{~V}$ for $30 \mathrm{~min}$.

The protein-bound PVDF membranes were incubated overnight at $4^{\circ} \mathrm{C}$ with the polyclonal GCLc antibody $(1: 3,000$; Abcam, Cambridge, UK) or monoclonal GCLm antibody (1:3,000; Abcam). The blots that were probed with the GCLc or GCLm antibody were incubated with the second antibody, goat anti-rabbit immunoglobulin G (1:3,000; Beijing Kangwei Technology Group Co., Ltd., Beijing, China) conjugated with horseradish peroxidase, at room temperature for $1 \mathrm{~h}$. The 5-bromo-4-chloro-3'-indolyl-phosphate p-toluidine-nitroblue tetrazolium chloride (Beijing Kangwei Technology Group Co., Ltd., Beijing, China) substrate was used for colorimetric visualization of the immunoreactions on the membranes. The immunoblots were imaged using a JS-680D automatic gel imaging analyzer (Shanghai Peiqing Science and Technology Co., Ltd., Shanghai, China). The band intensity of all the samples was normalized using glyceraldehyde 3-phosphate dehydrogenase as the standard. The intensity of the immunoreactions on the blots was quantified using Quantity One software (SensiAnsys; Shanghai Peiqing Science and Technology Co., Ltd., Shanghai, China).

Statistical analysis. Statistical analysis was performed using the SPSS 13.0 software (SPSS, Inc., Chicago, IL, USA). Data are expressed as the mean \pm standard deviation. The difference between the subject groups was analyzed using student's t-test independently. Correlations analysis was performed using Spearman's rank test. $\mathrm{P}<0.05$ was considered to indicate a statistically significant difference. All the figures were generated with the GraphPad Prism software, version 5.0 (GraphPad Software, Inc., La Jolla, CA, USA).

\section{Results}

Changes in enzymatic activity of GCL in RCC. GCL activity from $46 \mathrm{RCC}$ patients was analyzed. The average GCL activity in the tumor tissue from the RCC patients was $342 \pm 123 \mathrm{mmol} / \mathrm{min} / \mathrm{mg}$ protein, which significantly increased compared to the adjacent normal tissue $(98 \pm 21 \mathrm{mmol} / \mathrm{min} / \mathrm{mg}$ protein) $(\mathrm{P}<0.01)$ (Fig. 1). The association between the enzymatic activity of GCL and TNM staging was analyzed. The results demonstrated that the GCL activity levels positively correlated with TNM staging $(\mathrm{r}=0.68, \mathrm{P}<0.01)$ (Fig. 2).

Changes to the protein contents of GCL subunits in RCC. To understand why the GCL activity in the tumor tissue of RCC patients changed, the protein content of the two GCL subunits was determined.

The modifier subunit of GCL lowers the $\mathrm{K}_{\mathrm{m}}$ (increases the affinity) for glutamate and ATP, and increases the concentration of GSH required for GCL inhibition $\left(\mathrm{K}_{\mathrm{i}}\right)(24)$. The representative immunoblots (A) and a summary of the densitometric 


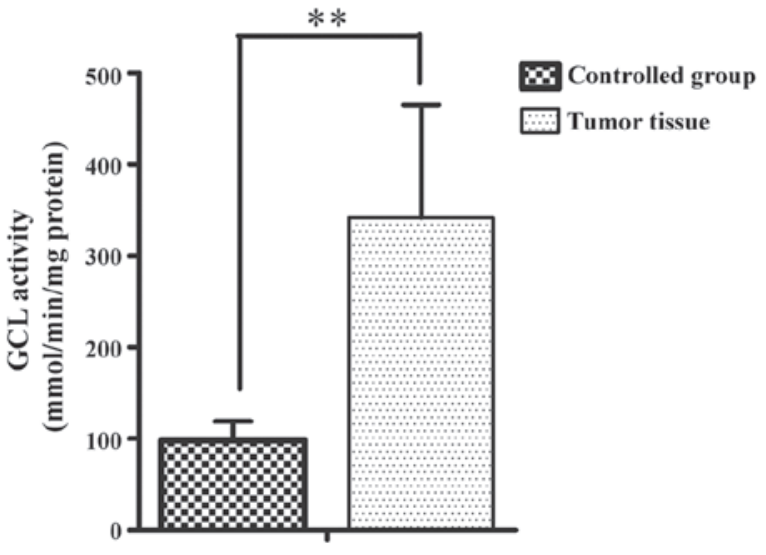

Figure 1. Glutamate cysteine ligase (GCL) activity in tumor tissue from renal cell carcinoma (RCC) patients and control group. GCL activity was measured from the RCC patients and control group ( $n=46)$. The GCL activity significant increased in RCC patients compared to the controls $($ *** $\mathrm{P}<0.01)$.

analysis (B) of GCLm from the RCC tumor tissue and adjacent normal tissue are shown in Fig. 3. In the tumor tissue, the relative GCLm contents were greater $(1.506 \pm 0.33, \mathrm{P}<0.01)$ compared to the values observed in the adjacent control tissue $(1.103 \pm 0.14)$.

The representative immunoblots (A) and densitometric analysis (B) of GCLc from the RCC tumor tissue and adjacent normal tissue are shown in Fig. 4. The relative content of GCLc in the RCC tumor tissue was significantly increased $(1.348 \pm 0.46, \mathrm{P}<0.05)$ compared to the values observed in the adjacent control tissue $(0.983 \pm 0.22)$.

Taken together, all these results showed that the changes in the protein content of the GCL subunits were found in the tumor tissue from the RCC patients.

\section{Discussion}

GSH is a significant intracellular antioxidant that generates a number of important roles within a cell, including drug detoxification, maintenance of the redox state and cellular protection from damage by free radicals, peroxides and toxins (15). Consequently, GSH has a critical role in several human diseases, including cancer and cardiovascular diseases (25). In the present study, the change in GCL protein expression and enzymatic activity was reported through western blotting and an activity assay in RCC patients, and through the positive correlation between GCL activity and TNM staging of RCC.

High intracellular GSH levels are significant contributors to pathologies, such as cellular transformation, resistance to radiation and antineoplastic treatments in cancer cells (15). The loss of intracellular GSH is an early indicator of cell death progression in response to different apoptotic stimuli and it is believed to be part of the changes involved in the generation of a permissive apoptotic environment that is necessary for the activation of apoptotic enzymes (26). A previous study has focused on utilizing the oxidative vulnerabilities of cancer cells and has led to the development of drugs that are specifically designed to disrupt the cellular redox balance and enhance the clinical effects of existing chemotherapy agents (27). The roles of the intracellular and extracellular redox state in the induction and maintenance of oxidative stress that is associated with

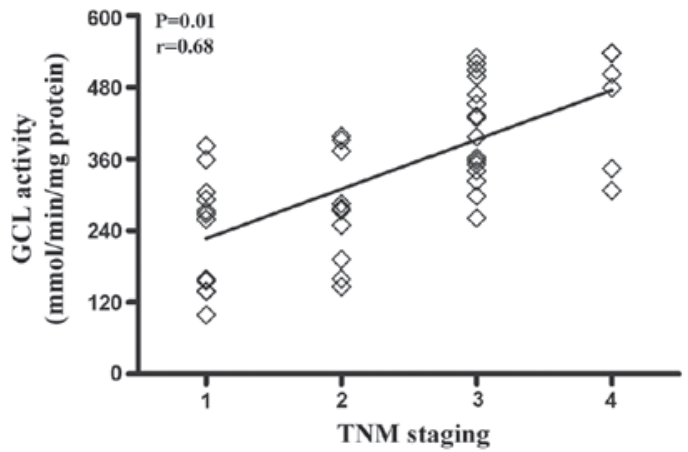

Figure 2. Positive correlation between glutamate cysteine ligase (GCL) activity and tumor-node metastasis (TNM) staging in renal cell carcinoma patients $(n=46)$.

A

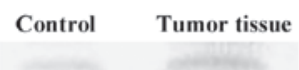

$\mathbf{B}$

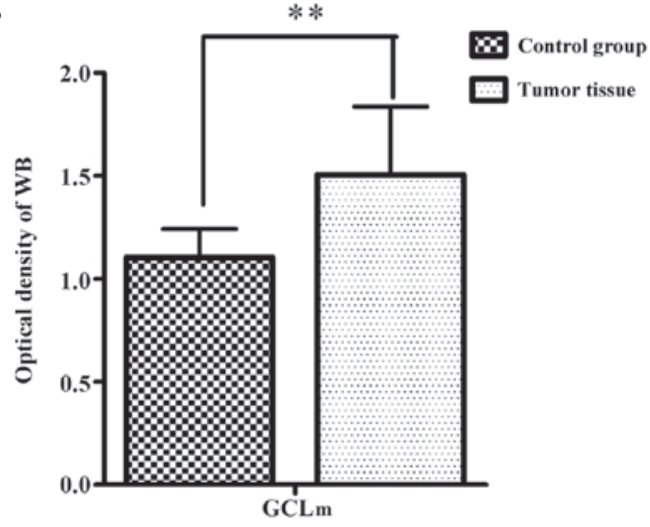

Figure 3. (A) Representative immunoblots and (B) content changes of glutamate cysteine ligase modulatory subunit (GCLm) are indicated from renal cell carcinoma (RCC) patients and the control group. Data are expressed as mean \pm standard error. ${ }^{* *} \mathrm{P}<0.01$. WB, western blotting.

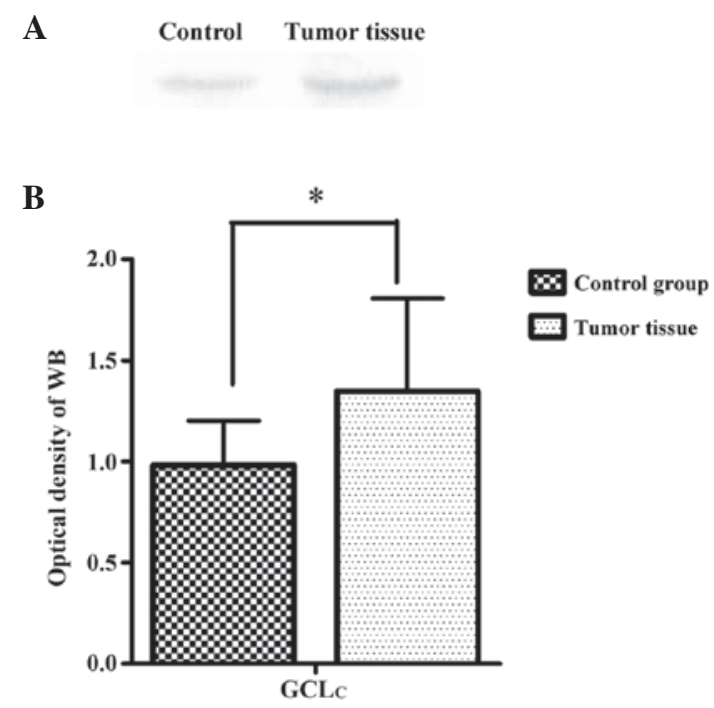

Figure 4. (A) Representative immunoblots and (B) content changes of glutamate cysteine ligase catalytic subunit (GCLc) are indicated from renal cell carcinoma (RCC) patients and the control group. Data are expressed as mean \pm standard error. ${ }^{*} \mathrm{P}<0.05$. WB, western blotting. 
cancer and metastasis via the activation of survival pathways, disruption of cell-death signaling and increase in cell proliferation has been shown previously (28).

In the present study, the protein expression levels of GCLc and GCLm and the enzymatic activity of GCL were shown to be significantly increased in the tumor tissue of the RCC patients, which may be an indicator of oxidative stress in RCC. Taken together, these results show the cause and consequence of the severity of the disease. These results suggest that the levels of GCL activity may be involved in RCC pathogenesis.

GCL catalyzes the first and rate-limiting step, in which glutamate is ligated with cysteine to form $\gamma$-GC, which is rapidly linked to glycine to form GSH via the action of GS (16). The present study showed that there is a good correlation between the GSH levels and GCL, which is the primary determinant of the rate of GSH synthesis (29). GSH-dependent detoxifying reactions protect cells from oxidative damage (30). In the last two decades, there has been much progress in the understanding of the roles of GSH in cancer cell biochemistry (31). GSH constitutes a major antioxidant defense system and together with the GSH-related enzymes, GSH is critical in protecting cells against free radical damage and controlling the tumor cell response to additional cancer therapies, such as irradiation and chemotherapy (32). Although there are potential benefits for cancer therapy using a selective GSH-depletion strategy, such a methodology has remained elusive thus far (28).

In conclusion, the present study showed that GCL enzymatic activity was upregulated and positively correlated with TNM staging in RCC patients. The results indicate that increasing GCL activity may correlate with the disease severity of RCC. The data provide support that oxidative stress may be a target for therapy or pharmacological agents of the RCC disease. The study indicates that the protein expression levels of GCLc and GCLm are increased in the renal tumor tissue from RCC patients compared to the adjacent controls. However, more in vitro and in vivo mechanistic studies are required to investigate the relationship between GSH and pathogenesis of RCC.

\section{References}

1. Shah D, Aggarwal A, Bhatnagar A, Kiran R and Wanchu A: Association between T lymphocyte sub-sets apoptosis and peripheral blood mononuclear cells oxidative stress in systemic lupus erythematosus. Free Radic Res 45: 559-567, 2011.

2. Lusini L, Tripodi SA, Rossi R, et al: Altered glutathione anti-oxidant metabolism during tumor progression in human renal-cell carcinoma. Int J Cancer 91: 55-59, 2001.

3. Ames BN, Shigenaga MK and Gold LS: DNA lesions, inducible DNA repair, and cell division: three key factors in mutagenesis and carcinogenesis. Environ Health Perspect 101 (Suppl 5): $35-44,1993$.

4. Moller $\mathrm{P}$ and Wallin $\mathrm{H}$ : Adduct formation, mutagenesis and nucleotide excision repair of DNA damage produced by reactive oxygen species and lipid peroxidation product. Mutat Res 410: 271-290, 1998.

5. Kongara S and Karantza V: The interplay between autophagy and ROS in tumorigenesis. Front Oncol 2: 171, 2012.

6. Kryston TB, Georgiev AB, Pissis P and Georgakilas AG: Role of oxidative stress and DNA damage in human carcinogenesis. Mutat Res 711: 193-201,2011.

7. Eltzschig HK and Carmeliet P: Hypoxia and inflammation. N Engl J Med 364: 656-665, 2011.

8. Yeh CC, Hou MF, Wu SH, et al: A study of glutathione status in the blood and tissues of patients with breast cancer. Cell Biochem Funct 24: 555-559, 2006.
9. Suess E, Malessa S, Ungersböck K, et al: Technetium-99m-d, l-hexaniethylpropyleneamine oxime (HMPAO) uptake and glutathione content in brain tumors. J Nucl Med 32: 1675-1681, 1991.

10. Grubben MJ, van den Braak CC, Nagengast FM and Peters WH: Low colonic glutathione detoxification capacity in patients at risk for colon cancer. Eur J Clin Invest 36: 188-192, 2006.

11. Peters WH, van Schaik A, Peters JH and van Goor H: Oxidisedand total non-protein bound glutathione and related thiols in gallbladder bile of patients with various gastrointestinal disorders. BMC Gastroenterol 7: 7, 2007.

12. Gupta A, Srivastava S, Prasad R, et al: Oxidative stress in non-small cell lung cancer patients after chemotherapy: association with treatment response. Respirology 15: 349-356, 2010.

13. Almadori G, Bussu F, Galli J, et al: Salivary glutathione and uric acid levels in patients with head and neck squamous cell carcinoma. Head Neck 29: 648-654, 2007.

14. Kearns PR, Pieters R, Rottier MM, Pearson AD and Hall AG: Raised blast glutathione levels are associated with an increased risk of relapse in childhood acute lymphocytic leukemia. Blood 97: 393-398, 2001.

15. Singh S, Khan AR and Gupta AK: Role of glutathione in cancer pathophysiology and therapeutic interventions. J Exp Ther Oncol 9: 303-316, 2012.

16. Ziegler DM: Role of reversible oxidation-reduction of enzyme thiols-disulfides in metabolic regulation. Annu Rev Biochem 54: 305-329, 1985.

17. Huang CS, Chang LS, Anderson ME and Meister A: Catalytic and regulatory properties of the heavy subunit of rat kidney gamma-glutamylcysteine synthetase. J Biol Chem 268: 19675-19680, 1993.

18. McConnachie LA, Mohar I, Hudson FN, et al: Glutamate cysteine ligase modifier subunit deficiency and gender as determinants of acetaminophen-induced hepatotoxicity in mice. Toxicol Sci 99: 628-636, 2007

19. Dalton TP, Dieter MZ, Yang Y, Shertzer HG and Nebert DW: Knockout of the mouse glutamate cysteine ligase catalytic subunit (Gclc) gene: embryonic lethal when homozygous, and proposed model for moderate glutathione deficiency when heterozygous. Biochem Biophys Res Commun 279: 324-329, 2000.

20. Iida T, Kijima H, Urata Y, et al: Hammerhead ribozyme against gamma-glutamylcysteine synthetase sensitizes human colonic cancer cells to cisplatin by down-regulating both the glutathione synthesis and the expression of multidrug resistance proteins. Cancer Gene Ther 8: 803-814, 2001.

21. Eble JN, Sauter G, Epstein JI and Sesterhenn IA (eds): Pathology and Genetics of Tumours of the Urinary System and Male Genital Organs. 1st edition. IARC Press, Lyon, pp12-43, 2004.

22. Edge S, Byrd DR, Compton CC, Fritz AG, Greene FL and Trotti A (eds): AJCC Cancer Staging Manual. 7th edition. Springer, New York, NY, pp103-115, 2010.

23. Chen CN, Brown-Borg HM, Rakoczy SG, Ferrington DA and Thompson LV: Aging impairs the expression of the catalytic subunit of glutamate cysteine ligase in soleus muscle under stress. J Gerontol A Biol Sci Med Sci 65: 129-137, 2010.

24. Franklin CC, Backos DS, Mohar I, White CC, Forman HJ and Kavanagh TJ: Structure, function, and post-translational regulation of the catalytic and modifier subunits of glutamate cysteine ligase. Mol Aspects Med 30: 86-98, 2009.

25. Locigno R and Castronovo V: Reduced glutathione system: role in cancer development, prevention and treatment (review). Int J Oncol 19: 221-236, 2001.

26. Kern JC and Kehrer JP: Free radicals and apoptosis: relationships with glutathione, thioredoxin, and the BCL family of proteins. Front Biosci 10: 1727-1738, 2005.

27. Montero AJ and Jassem J: Cellular redox pathways as a therapeutic target in the treatment of cancer. Drugs 71: 1385-1396, 2011.

28. Solinas G, Marchesi F, Garlanda C, Mantovani A and Allavena P: Inflammation-mediated promotion of invasion and metastasis. Cancer Metastasis Rev 29: 243-248, 2010.

29. Maher P: The effects of stress and aging on glutathione metabolism. Ageing Res Rev 4: 288-314, 2005.

30. Yuan J, Zhang Z, Li L and Song W: Resveratrol affects the expression of glutamate cysteine ligase in the kidneys of aged rats. Exp Ther Med 7: 1762-1766, 2014.

31. Estrela JM, Ortega A and Obrador E: Glutathione in cancer biology and therapy. Crit Rev Clin Lab Sci 43: 143-181, 2006.

32. Backos DS, Franklin CC and Reigan P: The role of glutathione in brain tumor drug resistance. Biochem Pharmacol 83: 1005-1012, 2012. 